\title{
REFLETINDO SOBRE A TRÍADE EDUCAÇÃO INFANTIL, EDUCAÇÃO DO CAMPO E REPRESENTAÇÕES SOCIAIS EM EDUCAÇÃO: UM ESTUDO SOBRE O ESTADO DA ARTE
}

\author{
Célia Gomez Sardinha da Silva ${ }^{1}$ \\ Edna Maria Querido de Oliveira Chamon ${ }^{2}$ \\ Nilsen Aparecida Vieira Marcondes ${ }^{3}$
}

Resumo: Considera-se relevante a reflexão sobre a tríade "Educação Infantil", "Educação do Campo" e "Representações Sociais em Educação" porque se constata a necessidade de se trazer continuamente para o debate questões pertinentes à importância dos temas principalmente quando voltados à construção da cidadania tanto nos contextos urbanos quanto rurais. Isso posto, objetiva-se com este estudo básico, exploratório e descritivo, caracterizado como estado da arte e utilizando-se dos descritores "Educação Infantil", "Educação do Campo" e "Representações Sociais em Educação" refletir sobre a temática proposta neste artigo. Conclui-se com a análise da tendência da produção científica que foi possível identificar a literatura disponível sobre os temas, indicar as lacunas existentes, bem como apontar para as questões que ainda necessitam de investigação científica.

Palavras-chave: Educação Infantil; Educação do Campo; Representações Sociais; Estado da Arte.

\footnotetext{
1 Programa de Pós-graduação em Educação e Desenvolvimento Humano (PPGEDH)/Universidade de Taubaté (UNITAU), Brasil. E-mail: cgsds@uol.com.br.

2 Programa de Pós-graduação em Educação e Desenvolvimento Humano (PPGEDH)/Universidade de Taubaté (UNITAU), Brasil. E-mail: edna.chamon@gmail.com.

3 Programa de Pós-graduação em Educação e Desenvolvimento Humano (PPGEDH)/Universidade de Taubaté (UNITAU), Brasil. E-mail: nilsenmarcondes@gmail.com.
} 